\title{
Computer Assisted Language Learning Social Networks: What Are They Talking about?
}

\author{
Andrew Laghos ${ }^{1}$, Efi Nisiforou ${ }^{2}$ \\ ${ }^{1}$ Department of Multimedia and Graphic Arts, Cyprus University of Technology, Limassol, Cyprus \\ ${ }^{2}$ Department of Education, University of Nicosia, Nicosia, Cyprus \\ Email: andrew.laghos@cut.ac.cy
}

How to cite this paper: Laghos, A. and Nisiforou, E. (2018) Computer Assisted Language Learning Social Networks: What Are They Talking about? Social Networking, 7, 170-180.

https://doi.org/10.4236/sn.2018.73014

Received: February 24, 2018

Accepted: July 20, 2018

Published: July 23, 2018

Copyright $\odot 2018$ by authors and Scientific Research Publishing Inc. This work is licensed under the Creative Commons Attribution International License (CC BY 4.0).

http://creativecommons.org/licenses/by/4.0/

\begin{abstract}
There are many reasons that motivate people to build online communities. The purpose of this study was to identify the topics that learners discuss when they are part of a computer assisted language learning course in order to answer the question "What are they talking about?". We have examined an e-community of 618 students who were learning the Modern Greek language online. We analyzed their conversation topics directly from the discussion boards of the web-based course and sorted them into the pre-defined topic categories. The results of the study showed that during the first lessons of the course the students contributed more to social discussions which were unrelated to the course material. The reason of this outcome is that the students want to introduce themselves and meet their peers. As they progressed through the course's lessons, however, their discussion topics became more course material related. The study ends with implications of the results and future research directions.
\end{abstract}

\section{Keywords}

Computer Assisted Language Learning, Social Networks, Students' Discussion Topics

\section{Introduction}

Traditional learning methods have gradually shifted from individual learning to cooperative learning because of the ubiquity of e-Learning [1]. Students usually engage in Computer-Mediated-Communication (CMC) when they are stuck, confused, excited, have questions, or just want to meet other peer students and have off topic discussions with them [2] [3] [4]. 
The main purpose of this study was to investigate what students talk about when they are part of a Computer Assisted Language Learning (CALL) social network community. CALL is defined as "the use of computers to help learn languages" (p. 368) [5]. CMC is "a process of human communication via computers, involving people, situated in particular contexts, engaging in processes to shape media for a variety of purposes" (p. 1) [2]. CMC has its benefits as well as its limitations. For instance, a benefit of CMC is that the discussions are potentially richer than face-to-face classrooms [4], but on the other hand, users with poor writing skills may be at a disadvantage when using text-based CMC [4]. Furthermore, asynchronous discussions allow for "reflective study followed by complex exchanges and genuine collaboration in the application of theory" (p. 1) $[3]$.

\section{Background}

There are many reasons that bring people together in online groups. These include but are not limited to hobbies, ethnicity, education, beliefs and just about any other topic or area of interest. An online community consists of a group of people, a shared purpose, policies and computer systems [6]. Thus, it is important to have tools that allow easy and straightforward ways for community members to interact with and support each other in a peer-to-peer fashion [7]. Online peer support occurs through the use of Computer-Mediated-Communication. The significance of students learning from their study peers is increasingly being recognized by the e-Learning community. In some cases, online learning can foster a greater degree of communication and closeness among students and tutors than face-to-face learning [3]. Furthermore, it has been shown that students prefer to contact their peer students rather than their tutor when they are struggling with coursework, facing difficulties in assessing facilities and understanding lectures [8].

Previous studies show that interaction is a fundamental process for learning [9] [10] and knowledge is constructed in Communities of Practice [11] through social interaction [12]. Researchers also noted that people who interact more in an online course tend to achieve higher marks on exams, as opposed to lurking which is not as successful [12]. When people find others that they feel are like them, they feel a connection and a deep understanding based on mutual experience [13].

Moreover, peer-support is an essential part of e-Learning [14]. Compared to individual and competitive learning, collaborative learning raises the students' achievement level and problem-solving activities and enhances the development of personal traits [15]. Additionally, another definition of online learning refers to the use of the Internet to access learning materials, to interact with the content, the instructor, and other learners as well as to obtain support during the learning process [16]. As a consequence, students are able to acquire knowledge, to construct personal meaning, and to grow from the learning experience [16]. 


\section{Methods}

A case study approach forms the methodological framework of this study. The case study was an online course for learning the Modern Greek language, entitled Learn Greek Online (LGO). LGO was developed through participatory design and distributed constructionism [17], is student-centered and facilities were provided that allow the students to engage in peer-support. The case study results in a rich and holistic account of a phenomenon anchored in real-life situations and provides insight and increases the readers' experiences [18] in their construction of knowledge [19]. In this study, the course and the 618 participants delimited the boundary of the case. The study participants were people with no knowledge of the Greek language, as well as bilingual members of the Greek Diaspora.

We relied on content analysis as a method of evaluating the discussions undertaken by the students during the online course. Content analysis is a social science methodology where recorded human communications are studied [20]. It is a technique used in qualitative analysis to study written material by breaking it down into meaningful units [20]. Topic Relation Analysis (TRA) method was used as the most appropriate model for the accomplishment of the discussions board content interpretation used for the purposes of the current study. In TRA [21] the student's postings were gathered directly from the discussion boards of the class and then clustered into the TRA categories. Participants, Threads and Messages were the units of analysis of the study. Specifically, the TRA categories along with their subcategories are as follows:

- A - Course material related. Category A deals with conversations in the discussion boards of the e-Learning courses that are related to the course material, and is broken down into two further categories, A1 and A2.

- A1 - Related to current Lesson. Threads that belong in A1 are conversations that have to do with the course material of the current lesson. Examples of such topics include questions and answers as well as correcting peers' mistakes.

- A2 - Related to course (but not the current lesson). Threads that belong in A2 are conversations that have to do with the course, but their subject is not in the current lesson's syllabus. For example, a conversation about an exercise of Lesson 3, posted in the discussion forum of Lesson 1, would go in this category. Also, a general question about mathematics (in an area that is not included in the Mathematics lesson's syllabus) would also fall within A2.

- B - Course websiteltechnical related. Category B is specific to conversations regarding the course website, and technical issues. Problems listening to audio files, accessing specific parts of the site, or usage issues are all included in this category.

- C - Not related to course. Finally, posts that are categorized in category C are those that have nothing to do with the course in hand or its usage and are generally described as free of course-related activities Category $\mathrm{C}$ has two 
sub-categories.

- $\quad$ C1 - Peer socializing. C1 is a broad category that covers conversation types where peers socialize with each other. Examples include students introducing themselves, discussions about football games and concerts, making new friends and so on.

- C2 - Other. Category C2 includes all the other off-topic conversations that are not about peers socializing with each other. Examples of posts that belong in this category are spam and advertisements.

The TRA categories are summarized in Table 1. LGO is not a mandatory course thus the students' online participation is completely voluntary. Unlike other courses where the students are required to post in the discussions allowing for experimental bias, LGO students contribute to the discussions because they want to and not because they have to. We documented the topic of the messages and conversation threads into the predefined TRA categories. In order to document and follow the evolution of the social network, the process was repeated 15 times in total (once for each of the 15 lessons).

\section{Results and Discussion}

Table 2 shows the participants in each TRA category per lesson for the LGO course. The Total and Unique Posters sometimes differ since the same student may have posted messages in the same lesson's forum, however, in multiple TRA categories. It can be seen that the majority of the students have posted in Lesson 1 's discussion board (506 of the 618 students).

The number of students who participated in the lessons' forums decreases after Lesson 1 with Lesson 2 having the second most participants (90 students). The participants in Lessons 3 to 15 range from 6 to 44 students, with Lesson 8 being the least productive one with only 6 students taking part.

Figure 1 shows the percentage of the participants' TRA category postings for the fifteen lessons. As can be seen, through the evolution of the course, the percentage of students who posted A1 related messages increased while participants posting in $\mathrm{A} 2, \mathrm{~B}$ and $\mathrm{C} 1$ decreased and there were no students posting messages that belong in the $\mathrm{C} 2$ category. Also, halfway through the course and more specifically for Lessons 7 and 8, all the posts were clustered in category A1 showing that the students who were participating were only interested in discussing the current lesson's material and not to socialize.

Table 3 shows the number of threads for each TRA category. The highest number of conversation threads appeared in Lesson 1 with a total of 216 present.

Table 1. TRA categories.

\begin{tabular}{ccc}
\hline A-Course Related & $\begin{array}{c}\text { B-Course Website/ } \\
\text { Technical Related }\end{array}$ & C-Not Related to Course \\
\hline $\begin{array}{c}\text { A1Related to current Lesson } \\
\text { A2 Related to course } \\
\text { (but not current lesson) }\end{array}$ & - & C2 Other \\
\hline
\end{tabular}


Table 2. Participant results.

\begin{tabular}{cccccccc}
\hline \multirow{2}{*}{ Lesson } & \multicolumn{2}{c}{ Course Related } & $\begin{array}{c}\text { Course Website/ } \\
\text { Technical Related }\end{array}$ & $\begin{array}{c}\text { Not Related } \\
\text { to Course }\end{array}$ & \\
\cline { 2 - 7 } & A1 & A2 & B & C1 & C2 & Total & Unique Posters \\
\hline L1 & 97 & 128 & 162 & 301 & 0 & 688 & 506 \\
L2 & 28 & 30 & 8 & 34 & 0 & 100 & 90 \\
L3 & 13 & 26 & 16 & 0 & 0 & 55 & 44 \\
L4 & 14 & 5 & 0 & 0 & 0 & 19 & 18 \\
L5 & 25 & 4 & 4 & 5 & 0 & 38 & 33 \\
L6 & 19 & 6 & 0 & 3 & 0 & 28 & 26 \\
L7 & 32 & 0 & 0 & 0 & 0 & 32 & 32 \\
L8 & 6 & 0 & 0 & 0 & 0 & 6 & 6 \\
L9 & 21 & 3 & 2 & 0 & 0 & 26 & 24 \\
L10 & 10 & 6 & 3 & 0 & 0 & 19 & 14 \\
L11 & 13 & 0 & 3 & 0 & 0 & 16 & 16 \\
L12 & 14 & 0 & 0 & 0 & 0 & 14 & 14 \\
L13 & 12 & 0 & 0 & 8 & 0 & 20 & 16 \\
L14 & 10 & 0 & 0 & 0 & 0 & 10 & 10 \\
L15 & 14 & 0 & 0 & 0 & 14 & 14 \\
\hline
\end{tabular}

Table 3. Threads results.

\begin{tabular}{ccccccc}
\hline \multirow{2}{*}{ Lesson } & \multicolumn{2}{c}{ Course Related } & $\begin{array}{c}\text { Course Website/ } \\
\text { Technical Related }\end{array}$ & $\begin{array}{c}\text { Not Related } \\
\text { to Course }\end{array}$ \\
\cline { 2 - 7 } & A1 & A2 & B & C1 & C2 & Total \\
\hline L1 & 36 & 58 & 61 & 61 & 0 & 216 \\
L2 & 10 & 4 & 3 & 1 & 0 & 18 \\
L3 & 4 & 7 & 5 & 0 & 0 & 16 \\
L4 & 4 & 2 & 0 & 0 & 0 & 6 \\
L5 & 10 & 2 & 2 & 2 & 0 & 16 \\
L6 & 6 & 3 & 0 & 1 & 0 & 10 \\
L7 & 12 & 0 & 0 & 0 & 0 & 12 \\
L8 & 2 & 0 & 0 & 0 & 0 & 2 \\
L9 & 6 & 1 & 1 & 0 & 0 & 8 \\
L10 & 5 & 2 & 1 & 0 & 0 & 8 \\
L11 & 4 & 0 & 1 & 0 & 0 & 5 \\
L12 & 5 & 0 & 0 & 0 & 0 & 5 \\
L13 & 4 & 0 & 0 & 1 & 0 & 5 \\
L14 & 5 & 0 & 0 & 0 & 0 & 5 \\
L15 & 5 & 0 & 0 & 0 & 5 \\
Total & 118 & 79 & 0 & 0 & 337 \\
\hline
\end{tabular}




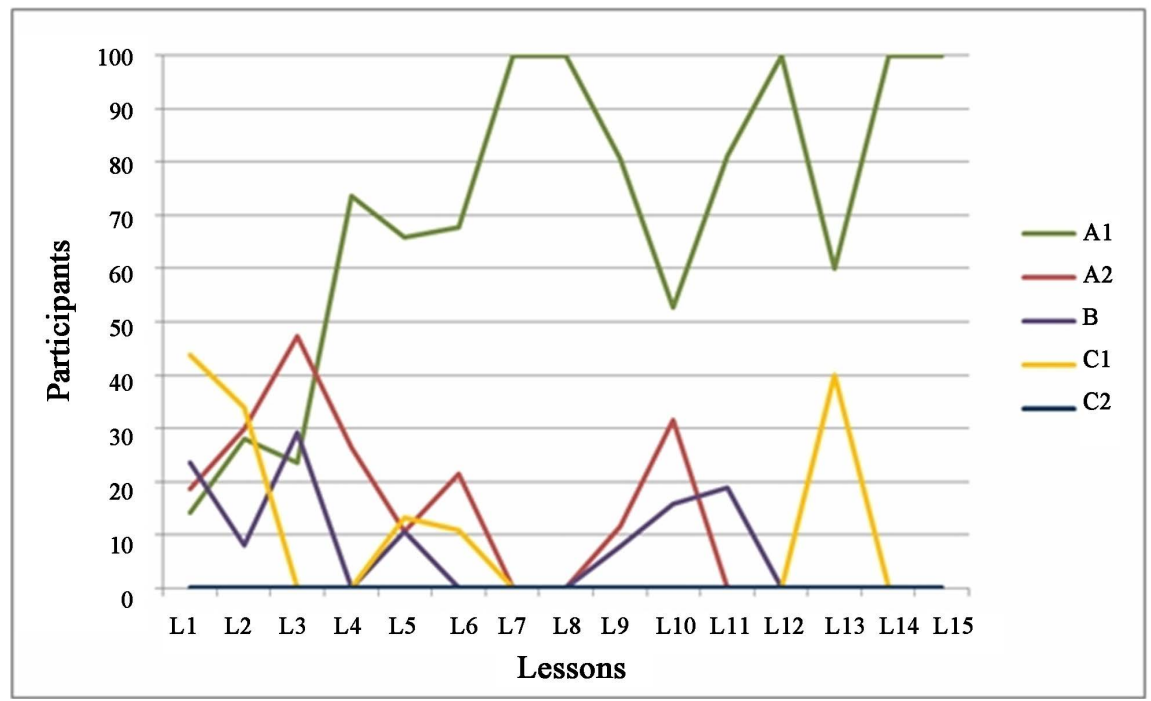

Figure 1. Evolution of participants per TRA category per lesson (\%).

There were a total of 337 threads in the studied course with the majority belonging in the A1 category (118), followed by the A2 category (79) showing that most of the conversation threads were related to the course in hand. Furthermore, there have been 74 threads in category B (Technical/website related) and 66 threads in the socializing category.

Figure 2 shows the percentage of threads in each category for every lesson. For the first three lessons the distribution is more evenly spread out between the TRA categories and they are balanced until about Lesson 3. After that, the majority of the threads become A1 related and in some instances (like Lessons 7 and 8) they are exclusively A1 threads with no other conversation topics involved. This indicates that although many of the conversations at the start of the course included peers socializing and asking questions about how to use the website, as the course evolved these diminished and mostly conversation threads on the course material emerged.

Table 4 shows the total number of messages posted by the students for each lesson. Most messages were posted in Lesson 1's discussion board (1230 of the 1821). It is interesting to note that although the distribution of threads in the TRA categories of Lesson 1 did not vary much, the actual number of messages does since 515 of the 1230 messages (41\%) were C1 related. This outcome portrays that the number of messages per thread is actually a lot more in the $\mathrm{C} 1$ category than in the rest of the TRA categories. As the course evolves however, once again there are more A1 related messages as a natural phenomenon since there were mostly A1 threads. In the last two lessons of the course all messages posted were in category A1.

Furthermore, a calculation of the percentages per TRA category of all the messages posted in the LGO course was held. The highest two were A1 (Related to current lesson) and $\mathrm{C} 1$ (Peer socializing) with $30 \%$ and $31 \%$ respectively. However, course material related messages (categories A1 and A2) made up the 


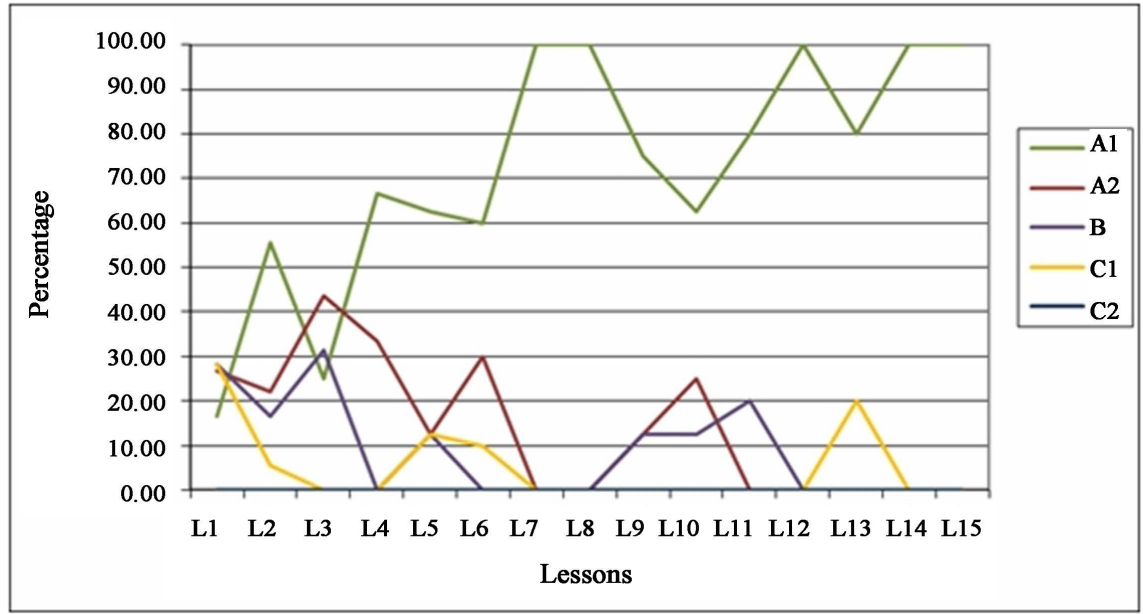

Figure 2. Percentage of threads per category by lesson.

Table 4. Messages results.

\begin{tabular}{ccccccc}
\hline \multirow{2}{*}{ Lesson } & \multicolumn{2}{c}{ Course Related } & $\begin{array}{c}\text { Course Website/ } \\
\text { Technical Related }\end{array}$ & $\begin{array}{c}\text { Not Related } \\
\text { to Course }\end{array}$ & \\
\cline { 2 - 6 } L1 & A1 & A2 & B & C1 & C2 & Total \\
\hline L2 & 166 & 280 & 269 & 515 & 0 & 1230 \\
L3 & 43 & 37 & 9 & 41 & 0 & 130 \\
L4 & 14 & 50 & 17 & 0 & 0 & 81 \\
L5 & 19 & 9 & 0 & 0 & 0 & 28 \\
L6 & 41 & 4 & 4 & 5 & 0 & 54 \\
L7 & 28 & 7 & 0 & 5 & 0 & 40 \\
L8 & 62 & 0 & 0 & 0 & 0 & 62 \\
L9 & 7 & 0 & 0 & 0 & 0 & 7 \\
L10 & 13 & 6 & 3 & 0 & 0 & 40 \\
L11 & 18 & 6 & 3 & 0 & 0 & 22 \\
L12 & 24 & 0 & 3 & 0 & 0 & 21 \\
L13 & 26 & 0 & 0 & 0 & 0 & 24 \\
L14 & 21 & 0 & 0 & 9 & 0 & 35 \\
L15 & 26 & 0 & 0 & 0 & 0 & 21 \\
Total & 539 & 399 & 0 & 0 & 26 \\
\hline & & & 0 & 0 & 1821 \\
\hline
\end{tabular}

bulk since they took up $52 \%$ of the total messages posted. Additionally, $17 \%$ of the messages were category B (Course web-site/technical related), and there were no $\mathrm{C} 2$ messages showing that the discussions did not contain any spam or advertisements and that the discussions were in a friendly and helpful atmosphere. Finally, Figure 3 shows the evolution of the messages cumulatively. The messages were calculated into percentages per TRA category for each lesson making it easier to follow. 


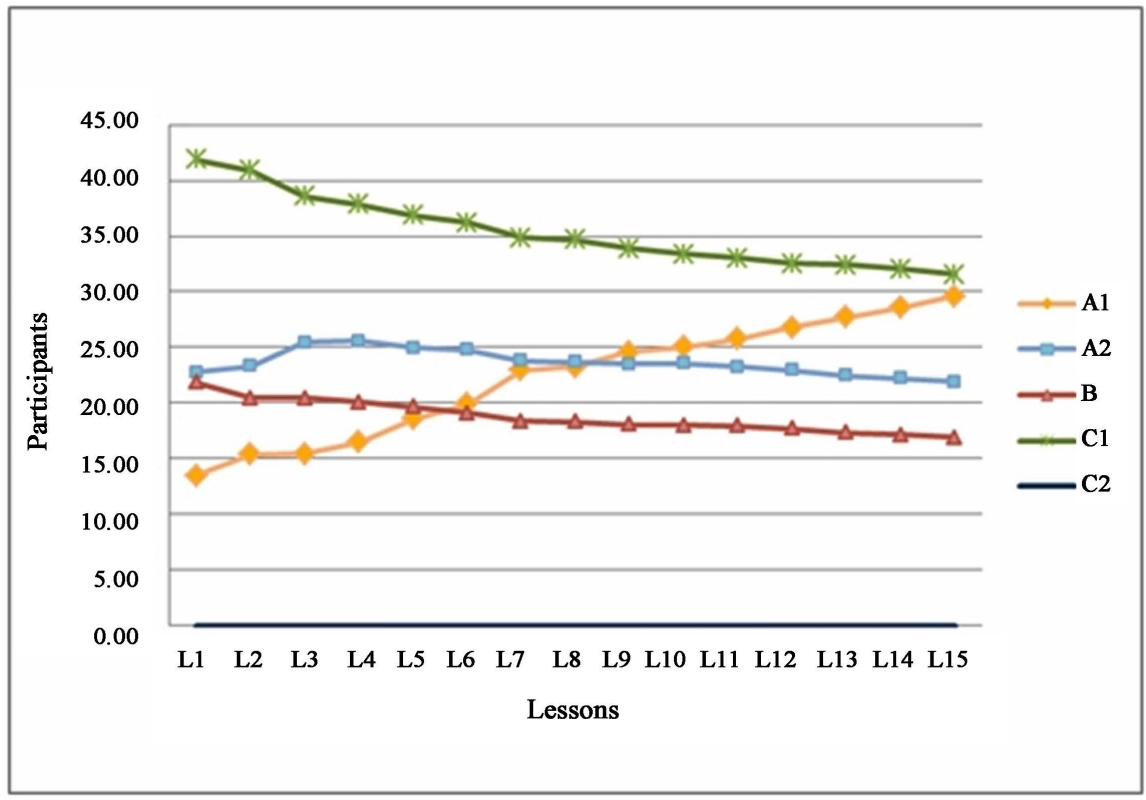

Figure 3. Cumulative messages (by percentage).

The most important thing to note here, is that $\mathrm{C} 1$ starts high and is on a gradual decrease, while A1 starts low and is on a gradual increase. They meet near the end of the course. Messages of categories B and A2 remained fairly constant over the course both ending with slightly lower percentages than at the beginning of LGO. All these indications lead to the conclusion that when the course started, the LGO students were more talkative and social with one another, but as the course progressed they became more relevant discussing topics and posting messages in the A1 category which was the one concerning to the course material and indeed the current lesson's material. In line with this outcome, previous studies have found that students are using social media to collaborate with their peers regarding course-related purposes [22].

The current study offers implications for practice and research. Firstly, there is a paramount importance to work with learners and assist them in establishing a community or feeling of connection in online contexts. Student orientation in online courses and student socialization with other online students greatly affected their success in the course [23] [24]. Creating a community of learners can improve student motivation and help facilitate the interpersonal and social interaction sought in an online classroom [25]. The current case study explored what students talk about during an online course, and the results are useful for instructors to rethink their practices in terms of effective instructional design for online courses and communicating with peers and instructors.

For course designers, it is recommended to implement scripts which can filter these conversations by topic and present them to the lecturers in a user-friendly way. Thus, lecturers will be able to easily see what their students are talking about. A benefit of this outcome is that if the instructor wants to increase the course related conversations, then he/she can intervene and begin new discus- 
sions on topics that they find will be more beneficial to the students.

\section{Conclusions}

Learning in Internet-based groups has a significant effect on student collaboration, cooperation, and co-construction of knowledge [26] [27] [28]. Students who are required to collaboratively work online need to dedicate time to get to know each other and therefore are able to accomplish effective communication in an online environment [29]. Many educators accept the intention that learning is a socially mediated process [8] [30], and that we develop knowledge through connections with other others. The results of the current study reveals that in order to create a sense of community, people must first get to know each other, communicate and socialize and then are able to discuss about more relevant topics of interest. In line with this thinking, group activities planned in advance can increase the feeling of social presence and learner-learner interaction [31]. Likewise, the findings of another study points out that student' motives in using social media are mainly concerning social issues [32].

Another outcome of the study pointed out that at the initial lessons of the course, the students posted more general course questions and social topics. As they progressed through the course lessons, however, their discussion topics became more focused to the applicable lesson material. This outcome tells us that the students seem to be more excited, talkative and social with one another, as well as chat/contribute more at the start of the course, but their overall participation rates were on a decrease during the duration of the course. These findings stress the importance of students interacting with each other when taking part in online learning courses.

\section{References}

[1] Chuang, P.J., Chiang, M.C., Yang, C.S. and Tsai, C.W. (2012) Social Networks-Based Adaptive Pairing Strategy for Cooperative Learning. Educational Technology \& Society, 15, 226-239.

[2] December, J. (1997) Notes on Defining of Computer-Mediated Communication. Computer-Mediated Communication Magazine, 3, 1-14.

[3] Sumner, J. and Dewar, K. (2002) Peer-to-Peer eLearning and the Team Effect on Course Completion. 2002 Proceedings of International Conference on Computers in Education, Auckland, 3-6 December 2002, 369-370. https://doi.org/10.1109/CIE.2002.1185949

[4] Scotcit (2004) Enabling Large-Scale Institutional Implementation of Communications and Information Technology. Using Computer Mediated Conferencing.

[5] Laghos, A. and Zaphiris, P. (2005) Computer Assisted/Aided Language Learning. Encyclopedia of Distance Learning, 1, 331-336. https://doi.org/10.4018/978-1-59140-555-9.ch050

[6] Preece, J. (2002) Online Communities: Designing Usability, Supporting Sociability. John Wiley and Sons, Chichester.

[7] Kurhila, J., Miettinen, M., Nokelainen, P. and Tirri, H. (2004) The Role of the Learning Platform in Student-Centered E-Learning. Proceedings of the 4 th IEEE 
International Conference on Advanced Learning Technologies, Joensuu, $30 \mathrm{Au}-$ gust-1 September 2004, 540-544. https://doi.org/10.1109/ICALT.2004.1357473

[8] Lockley, E., Pritchard, C. and Foster, E. (2004) Students Supporting Students-Lessons Learnt from an Environmental Health Peer Support Scheme. Journal of Environmental Health Research, 3, 74-81.

[9] Vygotsky, L.S. (1978) Mind in Society: The Development of Higher Mental Processes. Harvard University Press, Cambridge.

[10] Vrasidas, C. (2000) Constructivism versus Objectivism: Implications for Interaction, Course Design, and Evaluation in Distance Education. International Journal of Educational Telecommunications, 6, 339-362.

[11] Wenger, E. (1999) Communities of practice: The key to Knowledge Strategy, Knowledge Directions. The Journal of the Institute for Knowledge Management, 1, 48-93.

[12] De Angeli, A. and Sue, K. (2005) Learning Conversations: A Case Study into E-Learning Communities. Proceedings of the Interact E-Learning and Human-Computer Interaction Worskhop, Rome, 12-16 September 2005, 1-6.

[13] Mead, S., Hilton, D. and Curtis, L. (2001) Peer Support: A Theoretical Perspective. Psychiatric Rehabilitation Journal, 25, 134-141. https://doi.org/10.1037/h0095032

[14] Laghos, A. and Zaphiris, P. (2006) Sociology of Student-Centred E-Learning Communities: A Network Analysis. E-Society Conference, Dublin, 13-16 July 2006, 98-106.

[15] Hamburg, I., Lindecke, C. and Thij, H. (2003) Social Aspects of E-Learning and Blending Learning Methods. Proceedings of the 4th European Conference E-COMMLINE, Bucharest.

[16] Ally, M. (2004) Foundations of Educational Theory for Online Learning. In: Anderson, T. and Elloumi, F., Eds., Theory and Practice of Online Learning, Athabasca University, Athabasca, 3-31.

[17] Zaphiris, P. and Zacharia, G. (2001) Design Methodology of an Online Greek Language Course. Human Factors in Computing Systems, 1, 103-104. https://doi.org/10.1145/634067.634130

[18] Merriam, S.B. (1998) Qualitative Research and Case Study Applications in Education. Jossey-Bass, San Francisco.

[19] Stake, R.E. (1994) Case Studies. In: Denzin, N.K. and Lincoln, Y.S., Eds., Handbook of Qualitative Research, Sage, Thousand Oaks, 236-247.

[20] Babbie, E. (2004) The Practice of Social Research. Thomson/Wadsworth Learning, Belmont.

[21] Laghos, A. (2005) FESNeL: A Methodological Framework for Assessing the Evolutionary Structure of Social Networks in E-Learning. 11th Biennial JURE/EARLI Conference, Nicosia, 23-27 August 2005, 1.

[22] Salaway, G. and Caruso, J.B. (2010) The ECAR Study of Undergraduate Students and Information Technology. EDUCAUSE Center for Applied Research, Boulder.

[23] Lynch, M.M. (2001) Effective Student Preparation for Online Learning. http://ts.mivu.org/default.asp?show=article\&id=901

[24] Levy, S. (2003) Six Factors to Consider When Planning Online Distance Learning Programs in Higher Education. Online Journal of Distance Learning Administration, 6, 1-16.

[25] Vonderwell, S. (2003) An Examination of Asynchronous Communication Experiences and Perspectives of Students in an Online Course: A Case Study. The Inter- 
net and Higher Education, 6, 77-90. https://doi.org/10.1016/S1096-7516(02)00164-1

[26] Bailey, M. and Luetkehans, L. (2001) Practical Guidelines for Facilitating Team Activities in Web-Based Training. In: Khan, B., Ed., Web-Based Training, Educational Technology Publications, Englewood Cliffs, 235-243.

[27] Conrad, D. (2002) Deep in the Hearts of Learners: Insights into the Nature of Online Community. Journal of Distance Education, 17, 1-19.

[28] Lock, J.V. (2002) Laying the Groundwork for the Development of Learning Communities within Online Courses. Quarterly Review of Distance Education, 3, 295-308.

[29] Mason, R. (1998) Models of Online Courses. Asynchronous Learning Network Magazine, 2, 1-10.

[30] Scardamalia, M. and Bereiter, C. (1996) Student Communities for the Advancement of Knowledge. Communications of the ACM, 39, 36-37. https://doi.org/10.1145/227210.227220

[31] Vrasidas, C. and McIsaac, M. (2000) Principles of Pedagogy and Evaluation of Web-Based Learning. Educational Media International, 37, 105-111. https://doi.org/10.1080/095239800410405

[32] Brandtzæg, P.B. and Heim, J. (2009) Why People Use Social Networking Sites. 3rd International Conference on Online Communities and Social Computing, San Diego, 19-24 July 2009, 143-152. https://doi.org/10.1007/978-3-642-02774-1_16 